\title{
Clinical and financial audit of diagnostic protocols for lesions of the cerebellopontine angle
}

\author{
I R C Swan, S Gatehouse
}

\begin{abstract}
Objective-To assess the diagnostic efficiency and costs of protocols used for investigating patients with suspected lesions of the cerebellopontine angle.

Design-Prospective evaluation of tests of auditory brain stem responses and acoustic reflex thresholds, electronystagmography, and calorics. Positive test results were confirmed or refuted by high resolution computed tomography with intravenous enhancement.
\end{abstract}

Setting-Single general otolaryngology clinic in a teaching hospital.

Patients-270 consecutive patients with sensorineural hearing loss requiring investigation to exclude a lesion of the cerebellopontine angle.

Main outcome measures-Estimated costs of various diagnositic protocols and performance in detecting tumours of the cerebellopontine angle.

Results-Protocols including tests of auditory brain stem responses and acoustic reflex thresholds as sifting tests before computed tomography were clinically acceptable and presented considerable savings over the use of computed tomography in all patients ( $\$ 74000$ or $£ 84000 v £ 122000$ ). The use of electronystagmography and calorics could not be justified on clinical or financial grounds.

Conclusions - Audiological tests of auditory brain stem responses and acoustic reflex thresholds followed by computed tomography constitute the most cost effective protocol for ${ }^{\wedge}$ determining suspected lesions of the cerebellopontine angle.

Implications-The cost effectiveness of diagnostic protocols should be evaluated throughout the health service.

\section{Introduction}

Methods of testing for suspected tumours or other lesions of the cerebellopontine angle have long been debated, formerly about which audiological tests should be used, ${ }^{1-3}$ but behavioural audiological tests have now been largely superceded by electrophysiological tests. ${ }^{+6}$ The current debate is whether electrophysiological or radiological tests (that is, computed tomography) should be used. ${ }^{7}$

The present era of resource management reinforces the longstanding need to make the best use of available resources. Investigations that do not appreciably contribute to diagnosis should not be ordered, and decisions about which should be used demand both a clinical and a financial audit. Clinical audit in this instance entails assessing the efficiency of tests in solving a clinical problem (finding the appropriate number of lesions of the cerebellopontine angle) whereas financial audit entails following the various diagnostic protocols and attaching realistic costs to each to assess the total cost of investigating the population with suspected lesions.

Clinical audit of test performance must be carried out on a target population appropriate for the conclusions to be drawn. Numerous reports exist of test performance in specialised secondary and tertiary referral clinics, ${ }^{811-13}$ but test performance, particularly specificity, depends on the population being tested. The appropriate population in this case comprises patients with suspected lesions of the cerebellopontine angle after examination in a general otolaryngology clinic. In addition, account must be taken of those in whom no test result is obtainable for various reasons.

Moffat $e t a l^{8}$ calculated the costs of diagnosing a tumour of the cerebellopontine angle at between $£ 185$ and $£ 344$, depending on which radiological tests are required. These are the costs of tests used to come to the final diagnosis in a patient who has a tumour. They are misleading as they take no account of the much larger number of patients who are investigated but are found not to have a tumour. As the expected incidence of tumours in the population at risk in a general otolaryngology clinic is only $3-5 \%{ }^{10}$ patients who are eventually shown not to have a tumour account for the greater part of the cost incurred.

We carried out a prospective study in a general otolaryngology clinic to assess the efficiency of various audiovestibular tests in detecting potential tumours of the cerebellopontine angle. The aim was to detect all tumours while minimising the number of patients referred for expensive radiological investigation. The costs of the various investigative protocols were then calculated and compared to see whether audiovestibular tests rather than radiological tests could be economically and clinically justified.

\section{Patients and methods}

The study patients were 270 consecutive patients from a general otolaryngology clinic. These comprised all patients attending this hospital during 30 months in whom the consultant responsible thought it necessary to exclude a diagnosis of a tumour of the cerebellopontine angle because of an asymmetric sensorineural hearing loss or other lateralising sign or symptom not accounted for by an aetiological factor in the clinical history or examination. Most (254) had asymmetric sensorineural hearing impairment, often associated with unilateral tinnitus (132) or imbalance (100). The remaining 16 had unilateral tinnitus with normal hearing thresholds.

All patients underwent tests of auditory brain stem responses and acoustic reflex thresholds. Electronystagmography and calorics were also done on the first 93 patients but were then discontinued in the light of an initial analysis. All tests were performed using standard methods, details of which are available from us.

A tumour of the cerebellopontine angle was excluded by the presence of normal auditory brain stem responses or by normal findings on high resolution computed tomography with intravenous enhancement. Because the test of auditory brain stem responses has a reported sensitivity of $95 \%$ and the incidence of such tumours in a general otolaryngology clinic is low these exclusion criteria do not affect the results of this study. Eleven tumours were identified. Auditory brain stem responses were classified as normal if the interaural JI-V latency difference was $<0.2 \mathrm{~ms}$; if JI could not be identified an absolute JV latency difference $<0.3 \mathrm{~ms}$ was the 
criterion. Acoustic reflex thresholds were accepted as normal only if they were better than the 25 th centile for known cochlear hearing losses. ${ }^{15}$ Findings were considered to be normal on caloric testing if there was no canal paresis $>20 \%$. Canal paresis was measured by comparing the maximum slow phase velocity induced by the different stimuli. ${ }^{16} 17$

The cost of performing the audiovestibular tests was calculated by taking the annual cost of the equipmen (depreciation plus maintenance plus materials) divided by the number of times the equipment was used per year (including use other than for investigating suspected tumours of the cerebellopontine angle) to give an equipment cost per test and then adding on the cost of the work to perform the tests and an allowance for the patient's opportunity cost (that is, loss of earnings and travel expenses). For simplicity no allowance was made for overheads such as heating, lighting, and floor space. The accurate assessment of auditory brain stem responses requires skill and experience; the most appropriate person to do this is an audiological scientist, who would take about an hour to do the test and write a report. Electronystagmography and calorics can be done by an experienced medica technical officer, usually at grade 3 , helped by another person, probably at grade 1 . The testing would normally take one hour; the grade 3 medical officer would require extra time to interpret the test results and write a report. A grade 2 technician would be expected to be capable of carrying out acoustic reflex testing in about 25 minutes. Salary costs were taken a the middle of the appropriate pay scales; table I shows these costings.

TABLE I-Costs (£) of audiovestibular tests (unless otherwise stated)

\begin{tabular}{|c|c|c|c|}
\hline & $\begin{array}{l}\text { Auditory brain } \\
\text { stem responses }\end{array}$ & $\begin{array}{l}\text { Electronystagmography } \\
\text { and calorics }\end{array}$ & $\begin{array}{l}\text { Acoustic } \\
\text { reflexes }\end{array}$ \\
\hline \multirow{2}{*}{$\begin{array}{l}\text { (a) Capital cost } \\
\text { (b) Life expectancy } \\
\text { (years) }\end{array}$} & 15000 & 8000 & 6000 \\
\hline & 10 & 10 & 5 \\
\hline $\begin{array}{l}\text { (c) Annual } \\
\text { depreciation }(\mathrm{a} / \mathrm{b})\end{array}$ & 1500 & 800 & 1200 \\
\hline (d) Maintenance & 1500 & 400 & 600 \\
\hline (e) Calibration & 200 & & 200 \\
\hline (f) Disposables & 300 & 150 & 250 \\
\hline $\begin{array}{l}\text { (g) Annual cost } \\
(\mathrm{c}+\mathrm{d}+\mathrm{e}+\mathrm{f})\end{array}$ & 3500 & 1350 & 2250 \\
\hline $\begin{array}{l}\text { (h) No of patients per } \\
\text { year }\end{array}$ & 200 & 150 & 1000 \\
\hline $\begin{array}{l}\text { (i) Capital cost per } \\
\text { test }(\mathrm{g} / \mathrm{h})\end{array}$ & 17.50 & 9.00 & 2.25 \\
\hline $\begin{array}{l}\text { (i) Salary } \\
\text { (k) Patient's }\end{array}$ & 9.50 & 15.00 & 2.50 \\
\hline opportunity cost & 6.00 & 6.00 & 3.00 \\
\hline $\begin{array}{l}\text { Total cost per } \\
\text { test }(i+j+k)\end{array}$ & 33.00 & 30.00 & 8.00 \\
\hline
\end{tabular}

The cost of computed tomography was calculated by taking the time to perform the investigation and comparing this with the hourly cost of running the scanner in this hospital (that is, equipment and staff costs), though with no allowance for heating, lighting, and floor space. To this was added the cost of supplies of materials for intravenous enhancement and a further $£ 3$ for the patient's opportunity cost (see below), giving a total cost of $£ 108$.

The total cost of a test protocol was calculated by adding together the costs of the tests and a further allowance for the patient's opportunity costs incurred by hospital visits, comprising $£ 6$ per hour for loss of earnings and $£ 2$ for travel costs. As the initial hospital visit is unavoidable and is common to all protocols its opportunity cost to the patient was excluded. All audiovestibular tests were assumed to be performed at one visit. Two hours were allowed per visit for travelling and waiting for tests, thus $£ 14$ was added to the protocol cost for each subsequent hospital visit

\section{Results}

Sensitivity was calculated as the percentage of patients with tumours who did not show normal test results - that is, who were referred for further investigation - and includes patients in whom no result was obtained. It is incorrect to exclude patients with no result because the test must still have been attempted and therefore costs incurred. Specificity was calculated as the percentage of patients without tumours who did show normal test results, patients with no test results being regarded as having abnormal results for reasons stated previously.

Tests of auditory brain stem responses and acoustic reflexes were not done in 39 patients with hearing impairments worse than $90 \mathrm{~dB}$ hearing level (HL). Table II shows the sensitivity and specificity of the

TABLE II-Sensitivity and specificity obtained for audiovestibular tests $(\%)$

\begin{tabular}{lcc}
\hline & Sensitivity & Specificity \\
\hline Auditory brain stem responses & $95^{\star}$ & 63 \\
Acoustic reflex thresholds & 100 & 35 \\
Electronystagmography and calorics & 80 & 50 \\
\hline
\end{tabular}

^Assumed from other studies.

tests. The sensitivity of the test of auditory brain stem responses could not be calculated because of the study design, as computed tomography was not done if the response was normal. For calculating protocol performance it was assumed to be $95 \%$, which is in the middle of the range of reported sensitivity data. ${ }^{14}$ Some authorities claim $100 \%$ sensitivity for auditory brain stem responses, ${ }^{461318}$ though they claim to use the same criteria for normality in wave latencies as others. Presumably they have stricter criteria for accepting the presence of a response. With these sensitivities, specificities, and costs the clinical efficiency and economics of the various protocols were calculated. To avoid quoting fractions of patients, it was assumed that 1000 patients needed to be investigated. This is the predicted annual workload for a catchment population of 3000000 . Of the 1000 patients, 40 could be expected to have tumours of the cerebellopontine angle. Computed tomography for all these patients would cost $£ 122000$.

A commonly used protocol is to test patients for auditory brain stem responses and if they do not have normal responses to proceed directly to computed tomography. Table III shows the costs of using such protocols compared with that of computed tomography as the sole test and also the number of tumours that would be missed but would have been diagnosed by computed tomography with intravenous enhancement.

TABLE III-Financial and clinical comparisons of computed tomo graphy and auditory brain stem responses as screening tests for tumour of cerebellopontine angle per 1000 patients

\begin{tabular}{lcc}
\hline Protocol & Cost $(£ 000)$ & $\begin{array}{c}\text { No of tumours } \\
\text { missed }\end{array}$ \\
\hline $\begin{array}{l}\text { All patients have computed tomography } \\
\text { Abnormal auditory brain stem } \\
\text { responses }(\leqslant 60 \mathrm{~dB}) \rightarrow \text { computed } \\
\text { tomography }\end{array}$ & 122 & 0 \\
$\begin{array}{l}\text { Abnormal auditory brain stem } \\
\text { responses }(\leqslant 90 \mathrm{~dB}) \rightarrow \text { computed } \\
\text { tomography }\end{array}$ & 92 & 1 \\
& 89 & 1
\end{tabular}

If a cut off point of $60 \mathrm{~dB} \mathrm{HL}$ is taken in the auditory brain stem response test the annual savings would be $£ 30000$. Though the specificity of the test falls rapidly above this threshold, further cost savings may be made by taking a cut off point of $90 \mathrm{~dB}$ HL. Opinions differ about the level of hearing impairment at which testing of brain stem responses is not worth while. 
Using either of these audiometric cut off points in the protocol might miss on average one tumour per year, which would be visible on computed tomography. The reason why one rather than the apparent two tumours might be missed is that an appreciable number of our patients with tumours (four of 11) had severe hearing loss and proceeded straight to computed tomography whereas the quoted sensitivity of $95 \%$ is based on patients with sufficient residual hearing to do the test.

Many departments use a parallel protocol of a test of auditory brain stem responses and electronystagmography and calorics to minimise the number of computed tomograms. Either a strict or a loose criterion may be used for a parallel protocol. If a strict criterion is used, whereby both (all) tests have to show abnormal results, considerable savings may be made on subsequent stages because this maximises specificity. However, it minimises sensitivity and in this instance would lead to eight tumours being missed annually (table IV). If instead the patient proceeds to computed tomography when either (any) test shows an abnormal result, all 40 tumours will probably be detected, but the cost of the protocol will exceed that of computed tomography alone.

TABLE IV-Financial and clinical comparisons of protocols using a test of auditory brain stem responses and electronystagmography and calorics per 1000 patients

\begin{tabular}{lcc}
\hline Protocol & Cost $(£ 000)$ & $\begin{array}{c}\text { No of tumours } \\
\text { missed }\end{array}$ \\
\hline $\begin{array}{l}\text { Auditory brain stem responses and } \\
\text { electronystagmography and calorics: }\end{array}$ & & \\
2 positive $\rightarrow$ computed tomography & 106 & 8 \\
l positive $\rightarrow$ computed tomography & 159 & 0 \\
\hline
\end{tabular}

A test of acoustic reflexes may be combined with that of auditory brain stem responses in a parallel protocol with a fail either (loose) or fail both (strict) criterion or in a serial (contingent) protocol with either test first. As acoustic reflexes when used with a very strict criterion for normality have a sensitivity of $100 \%$ the sensitivity of any of these four protocols can be made the same. Even though acoustic reflexes have a poor specificity, their excellent sensitivity makes them economically valuable if facilities for measuring auditory brain stem responses are not available. Table $\mathrm{V}$ shows the cost of each protocol, assuming that patients with hearing thresholds worse than $90 \mathrm{~dB}$ HL proceed directly to computed tomography. This comparison illustrates that a serial protocol is cheaper than a parallel protocol and also that if a serial protocol is to be chosen then the cheaper test should be used first.

TABLE $\mathrm{V}-$ Financial and clinical comparisons of protocols combining tests of auditory brain stem responses and acoustic reflex thresholds per 1000 patients

\begin{tabular}{lcc}
\hline Protocol & Cost $(£ 000)$ & $\begin{array}{c}\text { No of tumours } \\
\text { missed }\end{array}$ \\
\hline $\begin{array}{c}\text { Acoustic reflex thresholds } \rightarrow \text { auditory } \\
\text { brain stem responses } \rightarrow \text { computed } \\
\text { tomography }\end{array}$ & 74 & 1 \\
$\begin{array}{c}\text { Auditory brain stem responses } \rightarrow \\
\text { acoustic reflex thresholds } \rightarrow \\
\text { computed tomography }\end{array}$ & 84 & 1 \\
$\begin{array}{c}\text { Auditory brain stem responses and } \\
\text { acoustic reflex thresholds: } \\
1 \text { positive } \rightarrow \text { computed tomography } \\
2 \text { positive } \rightarrow \text { computed tomography }\end{array}$ & 135 & \\
\hline
\end{tabular}

\section{Discussion}

Investigating suspected tumours of the cerebellopontine angle is a considerable workload for the average otolaryngology department. Because the incidence of the tumours is low few otolaryngologists have much experience of diagnosing them, and thus guidance on the most cost effective protocol based on quantitative analysis of an adequate set of data is useful. Clinical audit of investigative protocols is essential in guiding clinical practice. In a small subgroup of patients the clinician may consider the risk of disease to be much higher, usually owing to additional clinical signs; our conclusions are not applicable to this subgroup or to tertiary referral clinics.

Costing tests in the NHS is not easy. We have taken a simplistic approach and have not allowed for overheads such as electricity and building maintenance. The cost of performing tests will differ among centres. Some may use cheaper or more expensive equipment; we have based our estimates of cost on equipment we think is appropriate at present rather than on the equipment we use. Depreciation will vary, so we have chosen a straightforward accounting method resulting in capital obsolescence. Staff costs will also vary. Some may regard the hourly cost of the patient's time as low, but this hospital serves a predominantly low income population. Not all patients were employed, but insufficient biographical data were collected to allow for loss of leisure time. We have itemised the component costs so that others may compare these with local costs and judge how these might affect comparison of protocols. Though this method of estimating costs does not include sufficient overheads to achieve realistic absolute costs for charging, it allows sufficiently well controlled relative costs to be calculated to trade cost against information value when deciding on an optimum protocol.

Table IV shows that a protocol of auditory brain stem responses and electronystagmography and calorics with a fail both criterion is clinically unacceptable because it would miss eight tumours $(20 \%)$. The same protocol with a fail either criterion certainly achieves the desired result - that is, all tumours are detected. However, such a protocol is actually more expensive than simply referring all patients with a suspected tumour for computed tomography because the multiple investigations carry appreciable cost. In addition, such a protocol would entail patients spending more time being investigated and experiencing more discomfort. For these reasons computed tomography for all patients is preferable.

At first sight protocols including auditory brain stem responses present considerable financial savings over computed tomography for all patients, though these protocols might miss one tumour out of 40 . It must be remembered, however, that computed tomography also misses tumours. High resolution computed tomography with intravenous enhancement will detect only tumours larger than $1 \mathrm{~cm}$ in diameter. Smaller tumours are detected by magnetic resonance imaging, but its availability in the United Kingdom would need to increase widely before its being used in routine investigation. Other methods of detecting small tumours such as air meatography are invasive and have an appreciable morbidity; they are thus rarely recommended unless there are other clinical features which make a tumour of the cerebellopontine angle likely. The only alternative way to detect small tumours is to follow up patients. Routine follow up of all patients with a suspected tumour defeats the purpose of the protocol. However, it seems reasonable to expect that patients with small tumours that are not detectable on computed tomography fall within the group of patients with abnormal auditory brain stem responses rather than that with normal responses. ${ }^{5}$ Routine follow up of all patients with abnormal responses but normal findings in computed tomography would be much more feasible. Progression of hearing impairment might then be an indication for further investigation and might more than compensate for the tumours 
potentially missed because of normal auditory brain stem responses.

Acoustic reflexes have the advantages of being cheap, easy to perform, and usually immediately available. Despite their poor specificity their routine use would mean that about a third of patients could be reassured at their initial clinic visit and not require further investigation. However, the criteria used by us for normality are much stricter than those usually quoted, and they have not been widely used for this purpose. Further evaluation of sensitivity is necessary in a large group of patients with tumours.

This study shows that there are economic and clinical justifications for including tests of auditory brain stem responses and acoustic reflex thresholds in serial protocols for investigating suspected lesions of the cerebellopontine angle. With escalating health care costs many areas of clinical practice justify the close inspection that can generate such conclusions. Clinical audit should always take precedence over financial audit; when there are various options which are equally acceptable clinically, however, economic considerations may show some procedures to be more efficient than others, and these should be preferred.

We thank Professor M P Haggard for his helpful comments during the preparation of this paper.
1 Sanders JW, Josey AF, Glasscock ME. Audiologic evaluation in cochlear and eighth nerve disorders. Arch Otolaryngol 1974;100:283-9.

2 Johnson EW. Auditory test results in 500 cases of acoustic neuroma Arch Otolarnygol 1977; 103:152-8.

3 Jerger $S$, Jerger J. Evaluation of diagnostic audiometric tests. Audiology 1983;22:144-61.

4 Cashman MZ, Rossman RN, Nedzelski JM. Cerebellopontine angle lesions: an audiological test protocol. F Otolaryngol 1983;12:180-6.

5 Josey AF. Audiologic manifestations of tumors of the VIIIth nerve. Ear Hear 1987;8 (suppl): 19-21S.

$6 \mathrm{Harder} \mathrm{H}$. Audiovestibular tests in the diagnosis of cerebellopontine angle tumours. Acta Otolaryngol (Stockh) 1988; Suppl 452:5-11.

7 Anonymous. Imaging patients with suspected acoustic neuroma [Editorial] Lancet 1988;ii: 1294.

8 Moffat DA, Hardy DG, Baguley DM. Strategy and benefits of acoustic neuroma searching. $\mathcal{F}$ Laryngol Otol 1989;103:51-9.

9 Mair ISW, Okstad S, Laukli E, Anke IM. Screening for retrocochlear pathology. Scand Audiol 1988;17:163-9.

10 Hart R, Davenport J. Diagnosis of acoustic neuroma. Neurosurgery 1981, 9:450-63

1 Musick FE, Josey AF, Glasscock ME. Auditory brainstem response-interwave measurements in acoustic neuromas. Ear Hear 1986;7:100-5.

12 Thomsen J, Tos M. Diagnostic strategies in search for acoustic neuromas. Acto Otolaryngol (Stockh) 1988; Suppl 452:16-25.

13 Barrs DM, Olsson JE. The audiological evaluation of cerebellopontine angh tumor suspects: a review of tumor and non-tumor suspects. Otolaryngol Head Neck Surg 1987:96:523-32.

14 Turner RG, Shepard NT, Frazer GJ. Clinical performance of audiological and related diagnostic tests. Ear Hear 1984;5:187-94.

15 Priede VM, Coles RRA. Interpretation of loudness recruitment tests - some new concepts and criteria. $\mathcal{F}$ Laryngol Otol 1984;88:641-62.

16 Jongkees LBB. The caloric test and its value in the evaluation of the patient with vertigo. Otolaryngol Clin North Am 1973;6:73-93.

17 Norre ME. The unilateral vestibular hypofunction. Acta Otorhinolaryngol Bel 1978;32:421-68

18 Reimer A. Quantitative interpretation of audiological test battery. Scand Audiol 1987;16:101-8.

(Accepted 29 January 1991
Hounslow and Spelthorne

Health Authority,

Middlesex

Brian W Ellis, FRCs,

chairman, district audit

advisory committee

Tom Sensky, MRCPSYCH,

vice chairman, district audit

advisory committee

Correspondence to: $\mathrm{Mr} \mathrm{B} \mathrm{W}$ Ellis, Consultant Surgeon,

Ashford Hospital, Ashford,

Middlesex TW15 3AA.

BMf 1991:302:704-7

\section{Audit in Person}

\section{A clinician's guide to setting up audit}

\author{
Brian W Ellis, Tom Sensky
}

By April 1991 the Department of Health expects medical audit to be implemented in every hospital. The implementation of some district audit programmes has already been described..$^{12}$ In Hounslow and Spelthorne the district audit advisory committee was concerned with the need to disseminate an understanding of audit, dispel a fear of the process, and provide sufficient guidance to enable clinicians to implement audit. To that end it produced a guide of its plans and the necessary actions, which was sent to every consultant in the district. (The districts have two general hospitals: Ashford and West Middlesex University Hospitals.) A covering letter requested the consultants to complete a confidential questionnaire designed to help identify current strengths and deficiencies in audit, which is essential in planning how to share expertise and resources throughout the district. Within three weeks completed questionnaires had been received from more than $60 \%$ of the recipients. This paper is a synopsis of the circulated document.

\section{How to set up audit}

Intended for guidance rather than as a rulebook, the document had three principal aims.

- To review the background and basic principles of clinical audit

- To illustrate some of the methods of audit

- To give general guidance on implementing audit.

BACKGROUND AND BASIC PRINCIPLES

What is clinical audit? - The Department of Health defines audit as: "The systematic, critical analysis of the quality of medical care, including the procedures used for diagnosis and treatment, the use of resources, and the resulting outcome and quality of life for the

\section{Educational value of audit ${ }^{\star}$}

- Critical review of current practice and comparisons against predefined standards encourages acquisition and updating of knowledge

- Identification of key features of clinical practice allows relevant lessons to be learnt

- Through audit, it is possible to identify particular areas where knowledge could be improved or is deficient, suggesting the need for research

- Self evaluation and peer review are important components of postgraduate education

^Standing Committee on Postgraduate Medical Education

patient," and states that "an effective programme of medical audit will help to provide reassurance to doctors, their patients, and managers that the best quality of service is being achieved, having regard to the resources available." ${ }^{3}$ Clinical audit and resource management have much in common. The data required for both overlap considerably and the information derived in each is relevant to the other. ${ }^{4}$ However, clinical audit is the responsibility of clinicians and must be led by them. ${ }^{5}$ The district committee views audit as safeguarding the clinical care of patients against inappropriate change dictated by economy.

Educational aspects-The educational benefits of clinical audit (box) have been considered in depth by Batstone. ${ }^{6}$ The committee believes that reviewing the lessons arising from previous audit meetings and ensuring that the conclusions of those meetings have been acted on is fundamentally important. ${ }^{.}$Some departments have found it necessary to devote a whole meeting every six to 12 months to this purpose alone; i 